\title{
Microstructural Characterization of Irradiated U-7Mo/Al-5Si Dispersion to High Fission Density
}

\author{
J. Gan, B. D. Miller, D. D. Keiser, Jr., A. B. Robinson, J. W. Madden, \\ P. G. Medvedev, and D. M. Wachs
}

Nuclear Fuels and Materials Division, Idaho National Laboratory

P. O. Box 1625, Idaho Falls, ID, U. S. A. 83415-6146

\author{
Corresponding Author \\ Jian Gan \\ Nuclear Fuels and Materials Division \\ Idaho National Laboratory \\ P.O. Box 1625 \\ Idaho Falls, ID, U. S. A. 83415-6146 \\ Phone 1-208-533-7385 \\ Fax 1-208-533-7996 \\ E-mail Jian.Gan@inl.gov
}




\section{Abstract}

The fuel development program for research and test reactors calls for improved knowledge on the effect of microstructure on fuel performance in reactors. This paper summarizes the recent TEM microstructural characterization of an irradiated U-7Mo/Al-5Si dispersion fuel plate (R3R050) in the Advanced Test Reactor (ATR) at Idaho National Laboratory (INL) to $5.2 \times 10^{21}$ fissions $/ \mathrm{cm}^{3}$. While a large fraction of the fuel grains is decorated with large bubbles, there is no evidence showing interlinking of these bubbles at the specified fission density. The attachment of solid fission product precipitates to the bubbles is likely the result of fission product diffusion into these bubbles. The process of fission gas bubble superlattice collapse appears through bubble coalescence. The results are compared with the previous TEM work on the dispersion fuels irradiated to lower fission density from the same fuel plate. 


\section{Introduction}

TEM characterization with high magnification detail on microstructure and composition provides critical information in understanding fuel performance. The conventional TEM sample preparation of highly radioactive irradiated fuel imposes extreme technical challenges $\left[{ }^{1},{ }^{2}, 3\right]$. With recent advancements in TEM sample preparation using the focused ion beam (FIB) technique for irradiated fuels, the sitespecific TEM analysis to obtain the microstructural information from the areas of interest identified from scanning electron microscopy (SEM) becomes routinely available for the irradiated fuels $\left[{ }^{4}\right]$. The typical fuel design for the research and test reactors is the plate type of fuels either in dispersion or monolithic configuration with a fuel composition of uranium alloying with 7-10 wt.\% Mo $\left[{ }^{5},{ }^{6}\right]$. This U-Mo fuel composition has shown to be effective in stabilizing $\gamma$-phase (body center cubic) and improving fuel performance $\left[{ }^{7},{ }^{8}\right]$. The previous TEM work on a U-7Mo/Al-2Si dispersion fuel with a local fission density of $6.3 \times 10^{27}$ fission $/ \mathrm{cm}^{3}$ was carried out from a sample prepared using conventional method [ $\left.{ }^{9}\right]$. This paper will present the microstructural characterization of the U-7Mo/Al-5Si dispersion fuel plate (plate ID: R3R050) irradiated in the Advanced Test Reactor (ATR) at Idaho National Laboratory (INL) as a part of the RERTR-7 irradiation experiment.

Multiple TEM lamellas were prepared using FIB, which allows access to site-specific microstructural information that may not be accessible to samples prepared using conventional methods for highly radioactive irradiated fuels. The TEM results from this work are compared with that of previous work on samples under relevant irradiation conditions including the sample from low flux conditions $\left(3.0 \times 10^{21}\right.$ fissions $/ \mathrm{cm}^{3}$ and $102^{\circ} \mathrm{C}$ ). The mechanism of fission gas bubble superlattice (GBS) collapse and its potential impact on the break-away fuel swelling are discussed near the end. Some common microstructural features between the irradiated U-Mo fuel in this work and the irradiated $\mathrm{LWR} \mathrm{UO}_{2}$ fuels in the literature are also discussed $\left[{ }^{10},{ }^{11}\right]$. 


\section{Experiment}

A small piece $\left(\sim 1 \mathrm{~mm}^{3}\right)$ was cut from the irradiated fuel plate (ID: R3R050) with its local fission density and centerline irradiation temperature of $5.2 \times 10^{21}$ fissions $/ \mathrm{cm}^{3}$ and $130^{\circ} \mathrm{C}$, respectively, calculated using a PLATE code $\left[{ }^{12}\right]$. The SEM sample was prepared and characterized first; the corresponding results can be found elsewhere $\left[{ }^{13}\right]$. The SEM sample was then loaded into a FIB/SEM system to prepare TEM samples from the areas of interest identified in the SEM work. The SEM information produced during the FIB-TEM sample preparation process provides additional information that is complementary to the standard SEM data. TEM characterization was carried out using a JEOL 2010 TEM/STEM system equipped with $\mathrm{a} \mathrm{LaB}_{6}$ filament, a 16-bit high resolution digital camera $\left(2048 \times 2048\right.$ over $\left.6.45 \times 10^{-4} \mathrm{~m}^{2}\right)$ for imaging and a Si Drift Detector for composition analysis with Energy Dispersive Spectroscopy (EDS). The results summarized in this paper are collected from FIB-TEM samples made from two small cuts from the high flux location of the irradiated dispersion fuel plate. Some relevant SEM images during the FIB process are also included to assist the discussion.

\section{Results}

To better understand the TEM results, some relevant SEM images are included in this paper to help understand the relationship between SEM analysis of the dispersion fuel and the site-specific FIB-TEM samples. The SEM images during FIB-TEM preparation from the second cut are shown in Figure 1. Note that the SEM information extracted from the FIB-sectioned plan preserves much better undisturbed microstructure compared to that of a conventional mechanically polished surface. Some key information can be found in these SEM images. One is that the large bubbles in the interior of the fuel particles display a closed shell-type substructure consisting of a high concentration of solid fission product (SFP). It was confirmed by TEM that the substructure around or inside the bubbles is amorphous. Another important feature is that the round shape bubbles in the Si-rich amorphous layer on the fuel side of the fuel-matrix-interface (FMI) have significantly larger bubble size than that of the faceted bubbles in the fuel interior. A low magnification TEM montage image of the entire FIB-TEM sample is shown in Figure 
2, along with a detailed view of the boxed area showing areas marked with number 05-16. The associated selected area diffraction (SAD) patterns indicate the crystalline region (05-07) and amorphous region (0816). Composition data from the EDS measurement of spot 05 to 15 are listed in Table 1. It appears that at high fission density, even a local Si content greater than 1 wt.\% could destabilize the microstructure and turn U-Mo to amorphous. It is worth notice that the relative error in composition measurement using EDS in TEM is typically greater than $10 \%$ and can be worse when light or heavy element is included as discussed by Williams and Carter $\left[{ }^{14}\right]$.

\section{(Insert Figure 1)}

(Insert Figure 2)

Table 1. EDS composition measurement at location shown in Figure 2. (wt\%)

\begin{tabular}{|c|c|c|c|c|l|}
\hline Location & Al & Si & Mo & U & \multicolumn{1}{|c|}{ Note } \\
\hline 05 & 0.4 & 0.3 & 15 & 84 & crystalline \\
\hline 06 & 0.5 & 0.1 & 13 & 86 & crystalline \\
\hline 07 & 1.2 & 1.5 & 16 & 81 & crystalline \\
\hline 08 & 0.8 & 1.0 & 14 & 85 & amorphous \\
\hline 09 & 1.4 & 1.5 & 15 & 82 & amorphous \\
\hline 10 & 0.9 & 1.2 & 16 & 81 & amorphous \\
\hline 11 & 1.1 & 1.6 & 16 & 82 & amorphous \\
\hline 12 & 1.1 & 1.7 & 14 & 83 & amorphous \\
\hline 13 & 1.5 & 1.8 & 16 & 81 & amorphous \\
\hline 14 & 1.3 & 1.5 & 16 & 81 & amorphous \\
\hline 15 & 3.3 & 2.9 & 14 & 79 & amorphous \\
\hline
\end{tabular}

The detailed microstructure of the areas marked in Figure 2 can be found through high magnification TEM images shown in Figure 3 through Figure 6. This set of TEM images captured the process of GBS collapse and the formation of the large bubbles in the interior of the fuel grains that is believed to be originally dominated by the GBS bubbles at lower fission densities. Bubble coalescence appears to act as the mechanism for the development of the large bubbles inside the fuel grain. It was found that when the small bubbles coalesce into large bubbles, the shape of the large bubbles tends to be irregular as shown in Figure 5. The development of the large bubbles in the fuel is rather heterogeneous. While some areas have multiple large bubbles forming (see Figure 5), the other area is relatively clean without showing any 
coarsening such as the area (spot 11) shown in Figure 6. Note that at this fission density, there is no solid fission product precipitates present in the clean area although it had already turned amorphous.

(Insert Figure 3)

(Insert Figure 4)

(Insert Figure 5)

(Insert Figure 6)

The SEM analysis reveals that there are areas of clean microstructure without large bubbles, as shown in Figure 7, where the green box indicates where the FIB-TEM sample was prepared. A TEM montage overview image of the entire FIB-TEM sample from that area is shown in Figure 8 where the bottom side corresponds to the top surface as is shown in Figure 7. According to the SEM characterization, these clean areas cover approximately $15 \%$ of the sectioned surface area of fuel particles in a SEM sample. Composition measurements with EDS in STEM mode were performed for the spots marked with a number. The results are listed in Table 2 where spots 4 to 18 were from the clean area.

It can be estimated that for U-235 atom fission in LWR neutron spectrum, each fission event produces $\sim 0.234$ atoms of Mo. For U-7Mo fuel at the calculated fission density, the anticipated Mo content should increase to 9.1 wt.\%. However, the measured Mo content for the areas with and without large bubbles is noticeably higher with $13 \mathrm{wt} \%$ and $15 \mathrm{wt} \%$, respectively. Both Mo and $\mathrm{Zr}$ are high yield solid fission products. The high Mo from the EDS measurement may indicate that the actual local fission density could be significantly higher than the calculated fission density. One possible reason could be the peaking effect if the $\mathrm{Pu}-239$ fission is considered. Local $\mathrm{Zr}$ content is another indicator for local fission density. The slightly higher $\mathrm{Zr}$ in the clean zone (spot 4 -18) suggests that the local fission density in the clean area is no less than the surrounding areas filled with large bubbles. Therefore, the observed clean microstructure could not be attributed to the speculated lower local enrichment or fission density.

(Insert Figure 7)

(Insert Figure 8) 
Table 2. EDS composition measurement at spots marked in Figure 8. (wt.\%)

\begin{tabular}{|c|c|c|c|c|c|c|c|c|}
\hline Spot & $\mathbf{U}$ & Mo & $\mathbf{Z r}$ & $\mathbf{N b}$ & $\mathbf{X e}$ & Nd & $\mathbf{S r}$ & Other \\
\hline 1 & 82 & 12 & 3.5 & 2.5 & & & & \\
\hline 2 & 79 & 14 & 3.9 & 2.9 & & & & \\
\hline 3 & 79 & 14 & 4.6 & 1.2 & & & & \\
\hline 4 & 80 & 14 & 4.6 & 1.5 & & & & Clean area without large bubbles \\
\hline 5 & 79 & 13 & 4.8 & 2.5 & & & & Clean area without large bubbles \\
\hline 6 & 79 & 14 & 4.7 & 2.0 & & & & Clean area without large bubbles \\
\hline 7 & 78 & 14 & 5.0 & 2.6 & & & & Clean area without large bubbles \\
\hline 8 & 77 & 15 & 5.6 & 2.6 & & & & Clean area without large bubbles \\
\hline 9 & 77 & 15 & 5.8 & 2.0 & & & & Clean area without large bubbles \\
\hline 10 & 76 & 14 & 6.3 & 3.0 & & & & Clean area without large bubbles \\
\hline 11 & 74 & 17 & 5.9 & 3.0 & & & & Clean area without large bubbles \\
\hline 12 & 77 & 16 & 5.3 & 2.4 & & & & Clean area without large bubbles \\
\hline 13 & 74 & 16 & 5.5 & 4.3 & & & & Clean area without large bubbles \\
\hline 14 & 78 & 13 & 6.0 & 3.2 & & & & Clean area without large bubbles \\
\hline 15 & 76 & 16 & 4.4 & 3.1 & & & & Clean area without large bubbles \\
\hline 16 & 76 & 15 & 5.1 & 3.2 & & & & Clean area without large bubbles \\
\hline 17 & 78 & 15 & 5.3 & 2.1 & & & & Clean area without large bubbles \\
\hline 18 & 78 & 14 & 5.1 & 3.8 & & & & Clean area without large bubbles \\
\hline 19 & 80 & 13 & 4.3 & 2.8 & & & & \\
\hline 20 & 80 & 12 & 4.2 & 3.1 & & & & \\
\hline 21 & 78 & 15 & 4.1 & 2.8 & & & & \\
\hline 22 & 78 & 14 & 4.3 & 3.9 & & & & \\
\hline 23 & 78 & 14 & 4.7 & 2.6 & & & & \\
\hline 24 & 79 & 12 & 4.7 & 3.3 & & & & \\
\hline 25 & 79 & 13 & 5.1 & 3.3 & & & & \\
\hline 26 & 78 & 14 & 3.6 & 4.0 & & & & \\
\hline 30 & 65 & 12 & 8.6 & & 3.1 & 5.7 & 0.5 & $\mathrm{Y} / 0.5$, \\
\hline 31 & 78 & 14 & 6.2 & & & & 0.5 & $\mathrm{Y} / 0.2$ \\
\hline 32 & 10 & 1.9 & 13 & & & 1.1 & 28 & $\mathrm{Y} / 8.3, \mathrm{Ba} / 37$ \\
\hline 33 & & 0.4 & 13 & & 10 & & 31 & $\mathrm{Y} / 9.0, \mathrm{Ba} / 32, \mathrm{Ce} / 4.5$ \\
\hline
\end{tabular}

Detailed microstructure of the clean area with high magnification TEM image at zone [011] of U-Mo crystalline region reveals GBS fine bubbles, as shown in Figure 9. The GBS has a face-centered-cubic (fcc) structure, which is coherent but not isomorphic to the bcc structure of U-Mo host material. The measured average bubble size and the fcc superlattice constant are $3.6 \pm 0.4 \mathrm{~nm}$ and $12.2 \mathrm{~nm}$, respectively. The GBS bubble image is actually a projected image of a row of GBS bubbles along the zone axis [011] of the bcc U-7Mo fuel grain, as illustrated in the schematic drawing. The presence of high order ( 4) satellite spots in SAD pattern indicates the high degree of 3-D ordering for the GBS bubbles. Note that no solid fission product precipitate can be identified in this clean area, suggesting that the solid fission products are likely kept in solution where GBS remains stable. 
Since most of the large bubbles even at a size of a few hundred nanometers (see Figure 1, low right section) are associated with SFP precipitates and the fact that no SFP precipitates can be found in the area with GBS bubbles, it appears that the SFP can rather quickly precipitate out towards the large bubbles once GBS collapses. It suggests that the SFP that are kept in solution before GBS collapse may severely exceed the solubility. This may be attributed to the higher diffusion barrier created by the GBS bubbles. It again demonstrates the great benefit of maintaining a stable GBS in the irradiated U-Mo fuel.

(Insert Figure 9)

High magnification TEM image at zone [011] from spot 31 in Figure 8 is shown in Figure 10. This area is adjacent to the large clean area. This time no satellite spots can be identified in major diffraction spots of the SAD zone pattern. It suggests that just retaining bcc crystalline structure is not sufficient to maintaining the GBS in U-Mo fuel. It is also important to point out that when the area gets thick, the visibility of the GBS bubbles is also significantly degraded. This area contains a high density of defects with dislocations and possibly dislocation loops. The effect of high local dislocation density on the development of GBS is not clear. Previous TEM work on the irradiated U-Mo fuel revealed well-developed GBS around a dislocation segment but at a much lower dislocation density. The preferential accumulation of solid fission products at the large bubbles is shown in Figure 11 along with EDS measurements listed in Table 3. The spots 9-25 are for SFP precipitates and the results show high content of $\mathrm{Zr}, \mathrm{Sr}, \mathrm{Ba}, \mathrm{Ce}$, and Y for spots $11-16$.

(Insert Figure 10)

(Insert Figure 11) 
Table 3. EDS composition measurements for the spots marked in Figure 11. (wt\%)

\begin{tabular}{|c|c|c|c|c|c|c|c|}
\hline Spot & $\mathbf{U}$ & Mo & $\mathbf{Z r}$ & $\mathrm{Sr}$ & Ba & Nd & Other \\
\hline 1 & 85 & 13 & 2.2 & & & & \\
\hline 2 & 84 & 13 & 2.9 & & & & \\
\hline 3 & 84 & 13 & 2.9 & & & & \\
\hline 4 & 86 & 11 & 3.1 & & & & \\
\hline 5 & 85 & 12 & 2.7 & & & & \\
\hline 6 & 84 & 13 & 3.8 & & & & \\
\hline 7 & 83 & 14 & 2.9 & & & & \\
\hline 8 & 82 & 13 & 4.2 & & & & \\
\hline 9 & 58 & 11 & 4.3 & 4.2 & 8.6 & 5.0 & Ce_5.8, Y_2.3, Pd_1.3 \\
\hline 10 & 77 & 10 & 3.0 & 0.6 & 0 & 4.8 & $\mathrm{Ce} \_3.2, \mathrm{Y} \_0.6, \mathrm{Pd} \_0.3$ \\
\hline 11 & 6.5 & 0.9 & 13 & 18 & 22 & 2.6 & Ce_7.0, Y_15, Pd_5.6, Te_9.2 \\
\hline 12 & 6.6 & 1.3 & 21 & 24 & 7.8 & 1.2 & Ce_9.1, Y_16, Pd_1.1, Te_12 \\
\hline 13 & 7.6 & 1.4 & 17 & 17 & 14 & 4.0 & Ce_11, Y_17, Pd_2.7, Te_8.8 \\
\hline 14 & 9.5 & 0.2 & 14 & 20 & 23 & 1.4 & Ce_9.7, Y_18, Pd_0.7, Te_3.6 \\
\hline 15 & 3.9 & 0.8 & 10 & 31 & 24 & 0.7 & $\mathrm{Ce} \_8.4, \mathrm{Y} \_17, \mathrm{Pd} \_1.6, \mathrm{Te} \_1.5$ \\
\hline 16 & 4.6 & 1.4 & 24 & 25 & 15 & 0.2 & Ce_7.2, Y_17, Pd_2.2, Te_2.0 \\
\hline 17 & 23 & 1.1 & 4.7 & 26 & 16 & 5.0 & Ce_6.9, Y_7.5, Pd_0, Te_9.7 \\
\hline 18 & 63 & 5.7 & 5.2 & 13 & 6.2 & 0 & $\mathrm{Ce} \_2.8, \mathrm{Y} \_4.7, \mathrm{Pd} \_0, \mathrm{Te} \_0.1$ \\
\hline 19 & 82 & 13 & 2.5 & 0.4 & 0 & 0 & $\mathrm{Ce} \_1.4, \mathrm{Y} \_0, \mathrm{Pd} \_0, \mathrm{Te} \_1.0$ \\
\hline 20 & 64 & 11 & 3.6 & 5.2 & 7.0 & 2.8 & $\mathrm{Ce} \_3.5, \mathrm{Y} \_2.2, \mathrm{Pd} \_0, \mathrm{Te} \_1.1$ \\
\hline 21 & 78 & 12 & 2.2 & 0 & 1.4 & 1.7 & Ce_2.5, Y_0.4, Pd_0.2, Te_1.4 \\
\hline 22 & 71 & 10 & 2.5 & 2.1 & 3.3 & 3.7 & Ce_3.2, Y_0.7, Pd_0.6, Te_2.5 \\
\hline 23 & 78 & 12 & 1.8 & 0.5 & 1.6 & 1.7 & $\mathrm{Ce} \_2.1, \mathrm{Y} \_0.4, \mathrm{Pd} \_0.2, \mathrm{Te} \_1.8$ \\
\hline 24 & 81 & 12 & 2.6 & 0.2 & 0 & 1.4 & $\mathrm{Xe} \_1.1, \mathrm{Y} \_0.4, \mathrm{Pd} \_0.2, \mathrm{Te} \_1.6$ \\
\hline 25 & 64 & 10 & 3.3 & 0.9 & 1.2 & 9.8 & Xe_0.8, Y_1.1, Pd_0.7, Te_1.2 \\
\hline 26 & 83 & 11 & 3.0 & 0.2 & 0.4 & 0 & $\mathrm{Xe} \_1.2, \mathrm{Y} \_0.9, \mathrm{Pd} \_0, \mathrm{Te} \_0$ \\
\hline
\end{tabular}

The preferential accumulation of solid fission products at large bubbles is evident from both SEM and TEM characterization work of the irradiated U-Mo fuel. In many cases, the solid fission product precipitate accumulates inside the large bubble. Typical elements of these solid fission products detected by TEM-EDS include Zr, Sr, Y, Ce, Ba, Nd, Pd, Te, and Xe. Note that in the irradiated $\mathrm{UO}_{2}$ fuel, the solid fission product precipitates accumulates inside the large grain boundary bubbles $(>1 \mu \mathrm{m})$ consisting of the following 5-metals: Pd-Rh-Ru-Tc-Mo [ $\left.{ }^{10,11}\right]$. The STEM-EDS elemental mapping with an electron beam size of $25 \mathrm{~nm}$ is shown in Figure 12. It clearly shows the solid fission product of $\mathrm{Sr}$ accumulated inside the large bubbles. Mo, which has a higher fission yield than $\mathrm{Sr}$, was either too low or not detected in the solid fission product precipitate associated with a large bubble. It appears that the accumulation of a 
specific solid fission product element at the large bubble may depend on the solubility of that fission product in U-Mo fuel.

A TEM low-magnification overview image of a FIB-TEM sample across the fuel-matrix interface is shown in Figure 13. The average bubble size in the Si-rich amorphous layer is significantly larger than the bubbles in the interior of the fuel particle. Note that the width of the Si-rich layer is $\sim 3$ times that for the FMI layer. The high-magnification images of the fuel-matrix interface and an area of fuel interior containing residual GBS bubbles are shown in Figure 14 and Figure 15, respectively. Bubbles in the FMI layer along the fuel-matrix interface with medium size (white contrast) and small size (light contrast) is evident, as is shown in Figure 14.

(Insert Figure 12)

(Insert Figure 13)

(Insert Figure 14)

(Insert Figure 15)

Although the area shown in Figure 15 retains bcc crystalline structure, only a portion of this area displays residual GBS bubbles. Similar to TEM observation shown in Figure 2 for spot 05-07 and Figure 10 for spot 31 , the retaining of a bcc crystalline structure is a necessary but not sufficient condition to maintaining a stable GBS in the U-Mo fuel. A STEM-EDS composition line scan across the fuel-matrix interface is present in Figure 16. The two distinctive layers: 1) A fuel-matrix-interaction layer (lower Si and U) and 2) a Si-rich layer in the fuel (higher Si and U) are clearly demonstrated. According to Figure 13, the width of this Si-rich layer could be double or triple that of the FMI layer. Due to the development of significantly large bubbles in the Si-rich layer, it suggests that the Si effect in suppressing FMI could have a negative effect by forming a thick Si-rich amorphous layer in the fuel particle.

(Insert Figure 16) 


\section{Discussion}

The most important information from the characterization of the high flux U-7Mo/Al-5Si sample is the capturing of the GBS collapsing at the given fission density of $5.2 \times 10^{21}$ fissions $/ \mathrm{cm}^{3}$. Another key feature of the irradiated fuel microstructure is the heterogeneous nature. The fuel particle displayed microstructure from clean areas with highly ordered GBS bubbles only to the areas with many large bubbles associated with SFP precipitates, and from crystalline region with no GBS presence or only residual GBS bubbles to amorphous region showing the development of large bubbles at different stages. The information collected from this TEM work will be useful to develop a better understanding of the fuel performance in the reactor by focusing on the microstructural evolution that may have an important effect on the U-Mo fuel swelling behavior. Note that at the irradiation temperature of approximately $130^{\circ} \mathrm{C}$, the homologues temperature $\mathrm{T} / \mathrm{T}_{\mathrm{m}}$ for $\mathrm{U}-7 \mathrm{Mo}$ fuel alloy $\left(\mathrm{T}_{\mathrm{m}} \sim 1160^{\circ} \mathrm{C}\left[{ }^{15}\right]\right)$ is 0.28 and most of the SFP atoms are mobile under irradiation at this temperature.

The first issue to be discussed is the interplay between the fission gas bubbles and the SFP precipitation. The production of SFP is a driving force for fuel swelling before gas bubble swelling becomes important. Unlike the irradiated $\mathrm{UO}_{2}$ fuel where SFP precipitates develop at the grain boundary bubbles site and form 5-metal precipitates (Pd-Rh-Ru-Tc-Mo), the U-Mo fuel develops highly ordered GBS bubbles in the fuel. For all the irradiated U-Mo fuels examined so far, there is no convincing evidence of SFP precipitates present in the U-Mo where GBS is stable. It suggests that the SFPs are kept in solution when the GBS bubbles are present. It is speculated that GBS may significantly increase the diffusion barrier for SFP as a result of high hydrostatic stress on U-Mo lattice from over-pressurized GBS bubbles, thus suppressing the development of SFP precipitates. This is different than in oxide fuel where it is believed that SFP precipitates out first, and then preferentially absorbs fission gas atoms and forms large bubbles around the SFP precipitates. At GBS collapse significant fraction of the U-Mo matrix turns to amorphous and subsequently the SFP mobility increases and promotes SFP precipitation. 
The morphology of the large bubbles shown in Figure 1 (see the bottom pictures) reveals a closed shell-type substructure consisting mostly of SFP. This type of substructure was not reported for the irradiated $\mathrm{UO}_{2}$ oxide fuel. Note that the larger bubbles in the $\mathrm{Si}$ rich layer show a different morphology than that of the bubbles in the fuel interior. Since Si-rich zones in U-Mo turn amorphous rapidly under irradiation $(<1$ hour $)$, the SFP is expected to have a much higher mobility in amorphous areas and in interactions with each other to form SFP precipitates. The follow-on preferential association of fission gas atoms to these SFP precipitates could lead to the development of large bubbles in this layer, but with a much thinner shell-type substructure around these large bubbles. The large bubbles in the fuel interior, on the other hand, show more complex morphologies with some fully filled with SFP and others displaying a thick closed-shell-type substructure. This type of closed shell substructure of SFP suggests that the bubble forms first and the influx of SFP accumulating around the bubble results in a closed shell type SFP substructure. As shown in the SEM image taken during the FIB process in Figure 1, the distribution of these large bubbles in the fuel interior do not seem associated with grain boundaries, which is different from that at lower fission density. At low fission density of $\sim 3 \times 10^{21}$ fissions $/ \mathrm{cm}^{3}$, large bubbles are only found on the grain boundaries and often in lenticular shape. The significantly large bubbles developed in the Si-rich zone could be problematic because the local swelling rate can accelerate when the bubbles grow big, and there is no restraint that could slow down the growth of these large bubbles.

A fundamental understanding of the mechanism governing the GBS nucleation and collapse is equally important to develop a complete knowledge on fuel performance. The TEM analysis of this unique sample allows the capturing of the process of GBS collapse, as is shown in Figure 3 through Figure 6. The previous thought that the GBS will be retained as long as the U-Mo crystalline structure remains appears not to be true. The evidence of GBS collapse in both crystalline and amorphous at high fission density is clear. The development of large bubbles in the fuel grain interior appears to be driven by the coalescence of fine bubbles collapsed from the GBS. The irregular shape of the larger bubbles as a result of bubble coalescence indicates the complex interaction of the bubble evolution with its surrounding fuel material and SFP. It seems that the attachment of SFP precipitates to the large bubbles is 
rather quick at high fission density. This may be linked to the fact that the SFPs were supersaturated in U-Mo when the GBS is dominant.

It is believed that the uniformity of the fuel microstructure in the as-fabricated condition is important and may have a direct impact on the development of the irradiated microstructure. The term uniformity is specifically talking about the grain size and its distribution, the dislocation density, enrichment (U-235 distribution in the fuel), composition (Mo distribution in U-Mo), and residual stress and its distribution, which directly relates to the dislocation distribution. The heterogeneous microstructure shown in SEM image (Figure 7) and low magnification TEM montage image (Figure 8) demonstrate the inhomogeneity of the original microstructure and microchemistry on the development of the irradiated microstructure. At the given fission density, there is about $15 \%$ area fraction of the sectioned surface retains clean microstructure of stable GBS bubbles only where the rest of the sample areas is typical of high-burnup microstructure with a high concentration of large bubbles and significant portion of U-Mo fuel turned amorphous.

Although radiation-induced atomic displacement damage in the microstructure could develop loops and eventually a high density of network dislocations, the initial state of dislocation density and its associated residual stress state could have a strong impact on the microstructural evolution under irradiation that is dominated by energetic fission products $(\sim 80 \mathrm{MeV})$. Further investigation to identify the mechanism for the retaining of a stable GBS microstructure could have a strong impact on enhancing the fuel irradiation performance by a better fuel design or fabrication process control. The clean microstructure shown in the above-mentioned SEM and TEM images contains GBS only, as is shown in Figure 9. It was noticed that the measured average size and the superlattice constant of the GBS for the high fission density condition are almost identical to that of the low fission density condition, as is shown in the comparison in Figure 17. In fact, the plot of the GBS bubble size distributions shows good agreement, suggesting little change from each other except for the thin black line that represents the GBS bubble size measurement from a U-10Mo monolithic fuel plate, while the rest are for U-7Mo dispersion fuel plates. The missing GBS bubbles in the crystalline areas adjacent to the clean microstructure could be 
considered evidence on the potential negative impact of the high initial density dislocations on the development of GBS (see Figure 10).

\section{(Insert Figure 17)}

The EDS measurement of SFP at the large bubbles (Figure 11) in the fuel interior listed in Table 3 again confirms that these SFP precipitates contain different SFP element compared to that found in the irradiated $\mathrm{UO}_{2}$ oxide fuel. Instead of SFP precipitates of Pd-Rh-Ru-Tc-Mo as found in $\mathrm{UO}_{2}$, the SFP precipitates in the irradiated U-Mo fuel consist of Zr-Sr-Ba-Y-Ce (spots 11-17 in 
Table 3). Although Mo is a high fission yield SFP, it was barely detected in the SFP precipitates in UMo fuel. Unlike in $\mathrm{UO}_{2}$, it indicates that Mo atoms produced from fission in U-Mo fuel retain in U-Mo solution as a result of high solubility. The diffusion kinetics of the SFP in the irradiated $\mathrm{UO}_{2}$ and U-Mo fuel could be quite different. In additional to the anticipated strong impact of GBS on SFP diffusion, the difference between ceramic and metal as well as the difference in the fuel centerline temperature $(\mathrm{Tc}=$ $1000^{\circ} \mathrm{C}$ for $\mathrm{LWR} \mathrm{UO}_{2}$ vs. $\mathrm{Tc}=130^{\circ} \mathrm{C}$ for $\mathrm{U}-\mathrm{Mo}$ ) and temperature gradient may explain the different composition of SFP precipitates associated with the large bubbles.

The development of large bubbles in the Si-rich amorphous layer in fuel interior right next to the FMI indicates a problem when considering the effect of adding Si to the matrix of dispersion fuel to suppress FMI. For a better control on fuel swelling, every effort shall be made to keep the bubbles small and densely distributed in the fuel. The GBS formation is an excellent example in suppressing fuel swelling. The development of large bubbles could quickly tip the system balance from low rate swelling dominated by SFP and GBS bubbles to high rate swelling driven by the bubble coalescence or the rapid growth of large bubbles. It is believed that when bubbles are small, the growth of total cavity volume is dominated by gas atom production and vacancy participation is ineffective. However, when large bubbles developed, the vacancy participation may become much more effective and the growth of the total cavity volume is likely driven by vacancy influx to the large bubbles. This is evident when the interlinking of large bubbles occurs, and the break-away swelling begins. Since the Si-rich layer develops large bubbles much earlier, the strong participation of vacancies becomes obvious, and the resultant swelling problem can become severe in this narrow region, compared to the fuel interior.

It is known that gas bubble size and shape depends on bubble surface tension, surface energy, pressure inside bubble and surrounding hydrostatic pressure. In U-Mo fuel fission, these conditions keep changing as fission density increases as a result of defect production and chemical state change due to SFP. The difference in local structure and composition could have a large impact to the bubble size and morphology (see Fig. 1, Fig. 8 and Fig. 13). The chemical effect of Si destabilizing and Mo stabilizing on U-Mo $\gamma$-phase (bcc) in term of bubble development appear strong. The early development of large 
bubbles in Si rich layer in amorphous U-Mo is likely a combined effect of enhanced diffusion of Xe gas atoms, reduced bubble surface tension and enhanced vacancy participation. It appears GBS is effective in maintaining a high local hydrostatic pressure and keeping SFP in U-Mo solution. Various shape and size of bubbles in the U-Mo fuel particle interior could be related to different stage of bubble development that may be affected by local dislocation density, stress state, composition and SFP precipitates. At high fission density, bubble interlink is another important mechanism having strong impact on bubble size and shape and leading to breakaway swelling.

According to the code calculation, the U-7Mo dispersion fuel plate has a fuel plate centerline temperature of $136^{\circ} \mathrm{C}$ at the beginning of life and $124^{\circ} \mathrm{C}$ at the end of life. It suggests the effect of U-Mo fuel thermal conductivity degradation on the fuel plate centerline temperature appears insignificant. As a result, the fuel centerline temperature for U-Mo dispersion fuel plate typically decreases with fission density increases. This is likely the combined effects of small fuel particle size $(<100 \mu \mathrm{m})$, reduced fission rate when large bubble becomes dominant at high burnup and good thermal conductivity of U-Mo fuel matrix. However, when breakaway swelling begins, fuel plate can develop large blistering and eventually cause fuel plate failure.

Another intricate question relates to the difference in threshold fission density for break-away swelling of U-Mo monolithic fuel compared to dispersion fuel. A general trend was found from large numbers of post irradiation examination (PIE) of the irradiated U-Mo fuel plates that shows the breakaway swelling for dispersion fuel plate and monolithic fuel plate occurs at fission density of around $5 \times 10^{21}$ fissions $/ \mathrm{cm}^{3}$ and $7 \times 10^{21}$ fissions $/ \mathrm{cm}^{3}$, respectively. The root cause is not clearly understood. One reason could be that the dispersion fuel used U-7Mo fuel particles while most of the monolithic fuel used U-10Mo fuel foil. It is well known that higher Mo provides high stability of $\gamma$-phase in U-Mo fuel $\left[{ }^{16}\right]$. Considering the fluctuation of Mo in U-Mo fuel alloy, the U-7Mo in dispersion fuel could be potentially more problematic comparing to U-10Mo in monolithic fuel if the low Mo region of the fuel falls below 5-6 wt.\% Mo. These low Mo regions of the fuel have a less stable bcc structure that can result in the 
collapse of GBS earlier, which could result in the development of large bubbles prematurely, and thus the break-away swelling could kick in at a lower fission density for dispersion fuels. Note that Mo fluctuation is also found in the pre-irradiated U-Mo fuel plate $\left[{ }^{17}\right]$.

One possible effect is the role of $\mathrm{Pu}-239$ fission as a result of the peaking effect, which could be much stronger in dispersion fuel than that in monolithic fuels due to the large difference in fuel geometry between the two. If it is assumed that a standard fuel particle size of $100-\mu \mathrm{m}$ diameter is used for dispersion fuel and a fuel foil thickness of $250 \mu \mathrm{m}$ for monolithic fuel, then for the same amount of fuel material $(5 \mathrm{~cm} \times 10 \mathrm{~cm}$ U-Mo fuel foil for monolithic) the total surface area of U-Mo fuel particles for dispersion fuel will be approximately 7.5 times that for a monolithic fuel foil. Since most RERTR fuel plates were irradiated with neutron-spectrum of LWR type thermal reactors, with a typical irradiation time of $\sim 100$ days, the amount of $\mathrm{Pu}-239$ produced from the conversion of $\mathrm{U}-238$ by absorption of thermal neutrons is in general proportional to the fuel surface area. With a factor of 7.5 times difference on the total surface area of the fuel, the relative impact of $\mathrm{Pu}-239$ fission for monolithic fuel is expected to be much less in comparison to dispersion fuel. By including the additional fissions from $\mathrm{Pu}-239$, the actual fission density at the threshold for break-away swelling shall be noticeably higher than that calculated from the PLATE code for dispersion fuel. The difference on the actual threshold fission density for break-way swelling between the dispersion fuel and monolithic fuel may be reduced. The Mo content measured in the fuel interior is significantly higher than what is estimated from the calculated fission density in this work, and this may be evidence that supports this argument.

\section{Conclusions}

The irradiated U-7Mo/Al-5Si dispersion fuel plate (R3R050) with a calculated fission density and temperature of $5.2 \times 10^{21}$ fissions $/ \mathrm{cm}^{3}$ and $130^{\circ} \mathrm{C}$, respectively was characterized using TEM. The TEM results demonstrate heterogeneous microstructure ranging from the clean areas with GBS bubbles only to areas with high concentration of large bubbles decorated with SFP precipitates. The sequence of large bubble development after GBS collapse is captured and the coalescence of small bubbles dictates the 
process. The morphology of the large bubbles in the fuel interior suggests that SFP precipitation occurs after the large bubbles developed. It is found that the retention of the crystalline structure in the U-Mo fuel is necessary but not sufficient to maintain a stable GBS bubble structure. The SFP precipitates in the irradiated fuel consist of $\mathrm{Zr}$-Sr-Ba-Y-Ce, different from that of Pd-Rh-Ru-Tc-Mo 5-metal precipitates found in $\mathrm{UO}_{2}$. 


\section{Acknowledgments}

Acknowledgment is given to the INL Hot Fuel Examination Facility staff for producing the punching sample from fuel plate R3R050. This work was supported by the U.S. Department of Energy, Office of Nuclear Materials Threat Reduction (NA-212), National Nuclear Security Administration, under DOE-NE Idaho Operations Office Contract DE-AC07-05ID14517. Accordingly, the U.S. Government retains a nonexclusive, royalty-free license to publish or reproduce the published form of this contribution, or allow others to do so, for U.S. Government purposes.

\section{U.S. Department of Energy Disclaimer}

This information was prepared as an account of work sponsored by an agency of the U.S. Government. Neither the U.S. Government nor any agency thereof, nor any of their employees, makes any warranty, express or implied, or assumes any legal liability or responsibility for the accuracy, completeness, or usefulness of any information, apparatus, product, or process disclosed, or represents that its use would not infringe privately owned rights. References herein to any specific commercial product, process, or service by trade name, trademark, manufacturer, or otherwise, does not necessarily constitute or imply its endorsement, recommendation, or favoring by the U.S. Government or any agency thereof. The views and opinions of authors expressed herein do not necessarily state or reflect those of the U.S. Government or any agency thereof. 


\section{Figure Captions}

Figure 1. SEM images of a trench during FIB-TEM sample cutting process revealing morphology of large bubbles in the fuel particle and at the fuel/matrix interface. Note that the large bubbles in the fuel particle display a closed shell-type substructure consisting of high solid fission product. Significantly larger bubbles are observed in the Si-rich amorphous layer (low right).

Figure 2. A TEM overview of FIB-TEM sample (top) and the magnified view of the boxed area near the top edge (bottom) with the selected area diffraction patterns (right) showing crystalline (05-08) and amorphous (09-15) region of the sample.

Figure 3. TEM images show complex GBS collapse in the fuel particle at crystalline (left, 06 in Figure 2) and amorphous (right, 08 in Figure 2) region.

Figure 4. TEM images show complex process of GBS collapse in the amorphous region of irradiated UMo fuel (10 and 12 in Figure 2). Bubble size distribution is much broader than that of GBS bubbles.

Figure 5. TEM images show GBS collapse and the formation of large bubbles through bubble coarsening.

Figure 6. TEM image shows a neighboring amorphous area (11 in Figure 2$)$ with only small bubbles without sign of bubble coarsening.

Figure 7. SEM image of an area shows clean microstructure without large bubbles.

Figure 8. TEM samples prepared from the area showing island of clean microstructure without large bubbles. The sample area is $10 \times 10 \mu \mathrm{m}^{2}$. The \# marks the spots where EDS measurement was taken.

Figure 9. High magnification TEM bright field image at zone [011] reveals GBS fine bubbles in the clean area without large bubbles (top) along with the selected area diffraction pattern showing satellite spots indicating high degree of 3-D ordering of the fine bubbles.

Figure 10. High magnification TEM image of the spot-31 area at zone [011] shows no GBS bubbles.

Figure 11. TEM image shows solid fission products preferentially associated with large bubbles.

Figure 12. STEM-EDS elemental mapping images of the irradiated U-Mo fuel.

Figure 13. FIB-TEM sample across the fuel-matrix-interface reveals $\mathrm{Al}$ alloy matrix (A), fuel-matrix interaction layer (B), the Si-rich amorphous layer in the fuel (C), and the fuel particle interior (D).

Figure 14. High magnification TEM image of the FMI-matrix interface near spot B in Figure 13 shows spherical bubbles in white and light contrast populated in FMI layer.

Figure 15. Fuel interior (near spot D in Figure 13) showing residual GBS bubbles at zone [011] in crystalline region.

Figure 16. STEM image (top) shows the EDS line scan path from Si rich layer in the fuel particle to Al alloy matrix and the corresponding composition profile (bottom).

Figure 17. Comparison of GBS bubbles in the irradiated U-7Mo/Al-5Si (R3R050) dispersion fuel plate in high flux (this work) (top-left) and low flux (previous work) (top-right) along with GBS bubble size distributions measured from relevant irradiation conditions (bottom). Red solid line: U-7Mo/Al-5Si high 
flux, Black dashed: U-7Mo/Al-5Si low flux, Thick grey-dashed: U-7Mo/Al-2Si high flux, Red dot line: U-7Mo/Al-2Si low flux, Thin black-solid: U-10Mo/Al low flux (monolithic plate). 
Figures

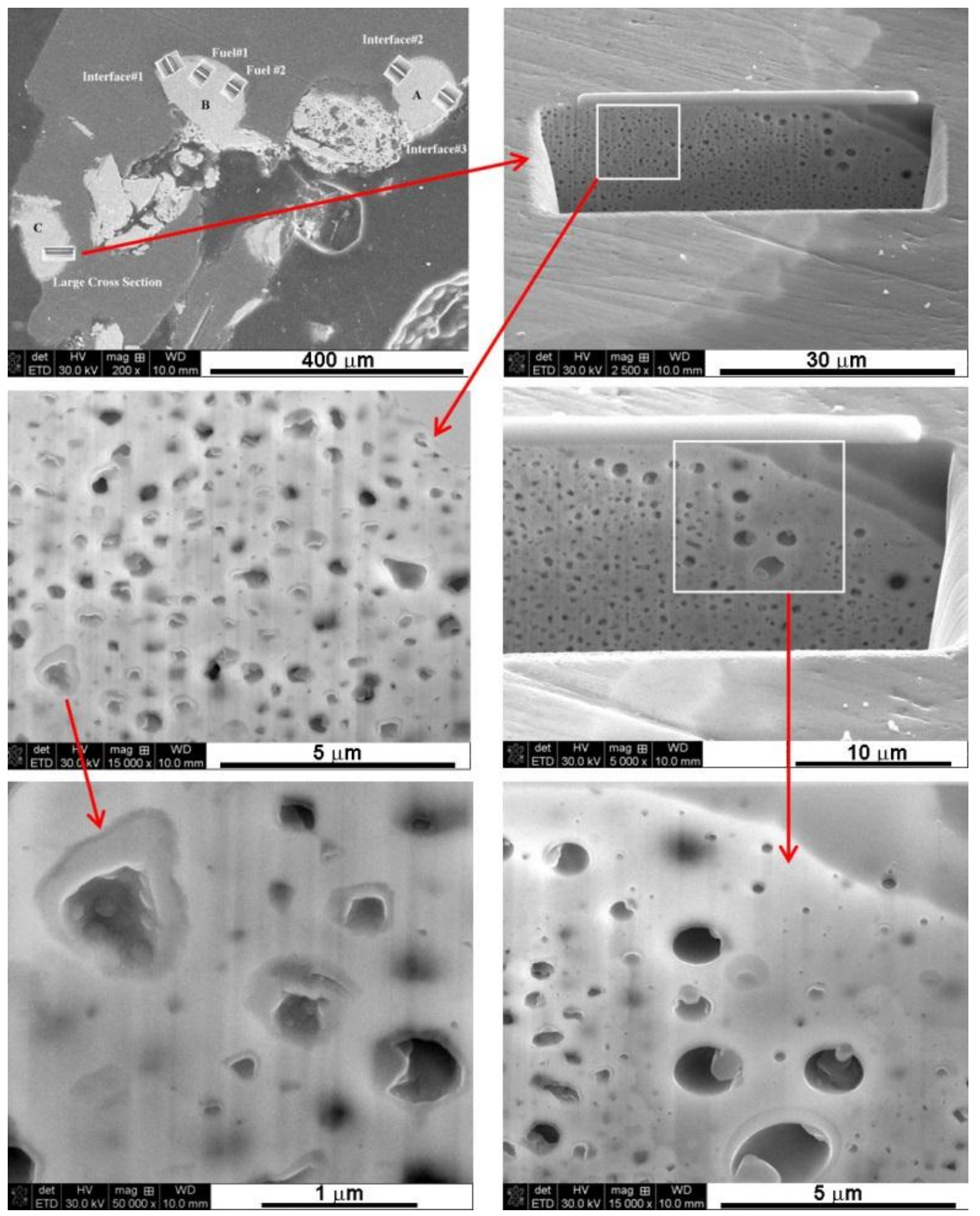

(Figure 1) 

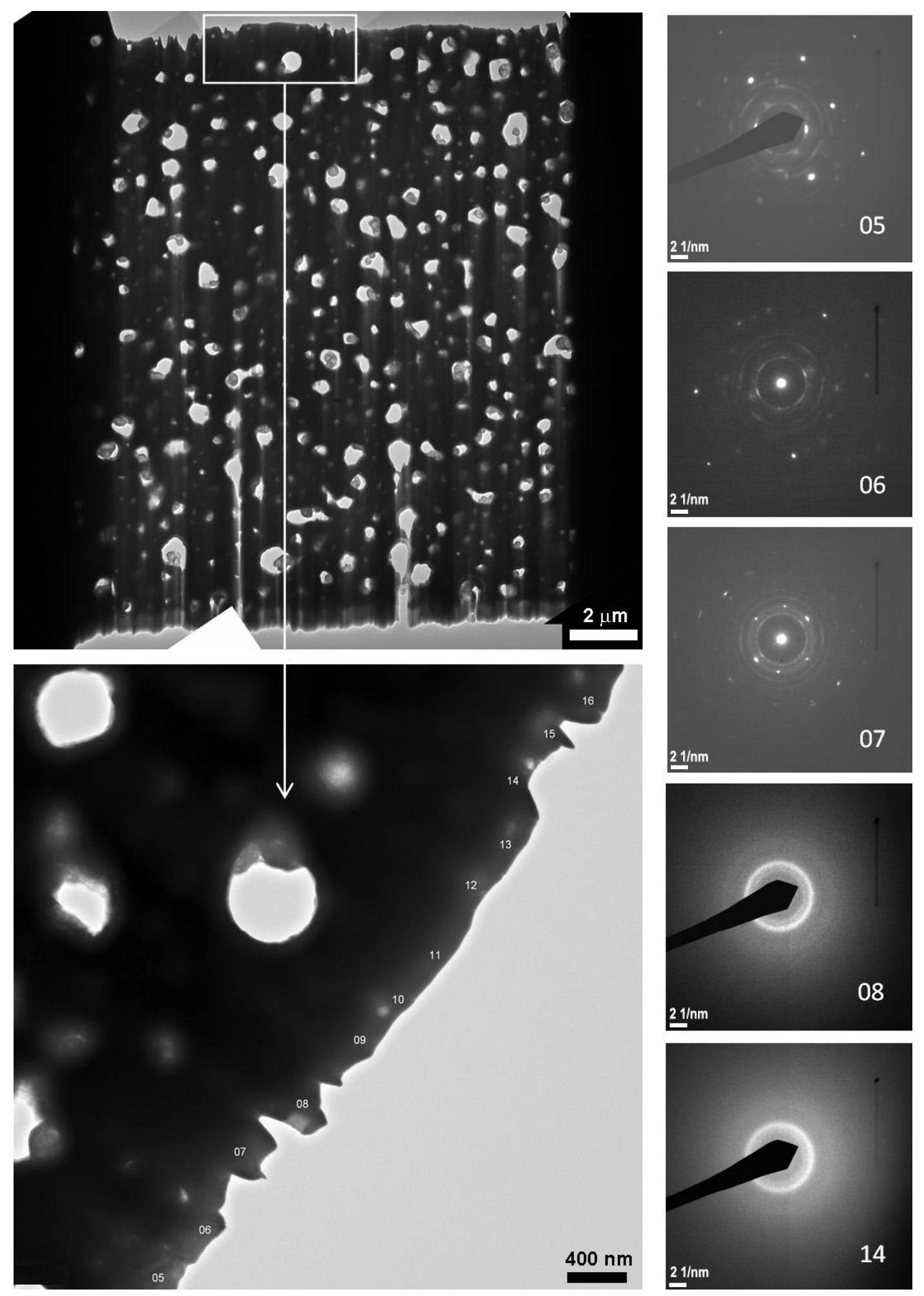

(Figure 2) 


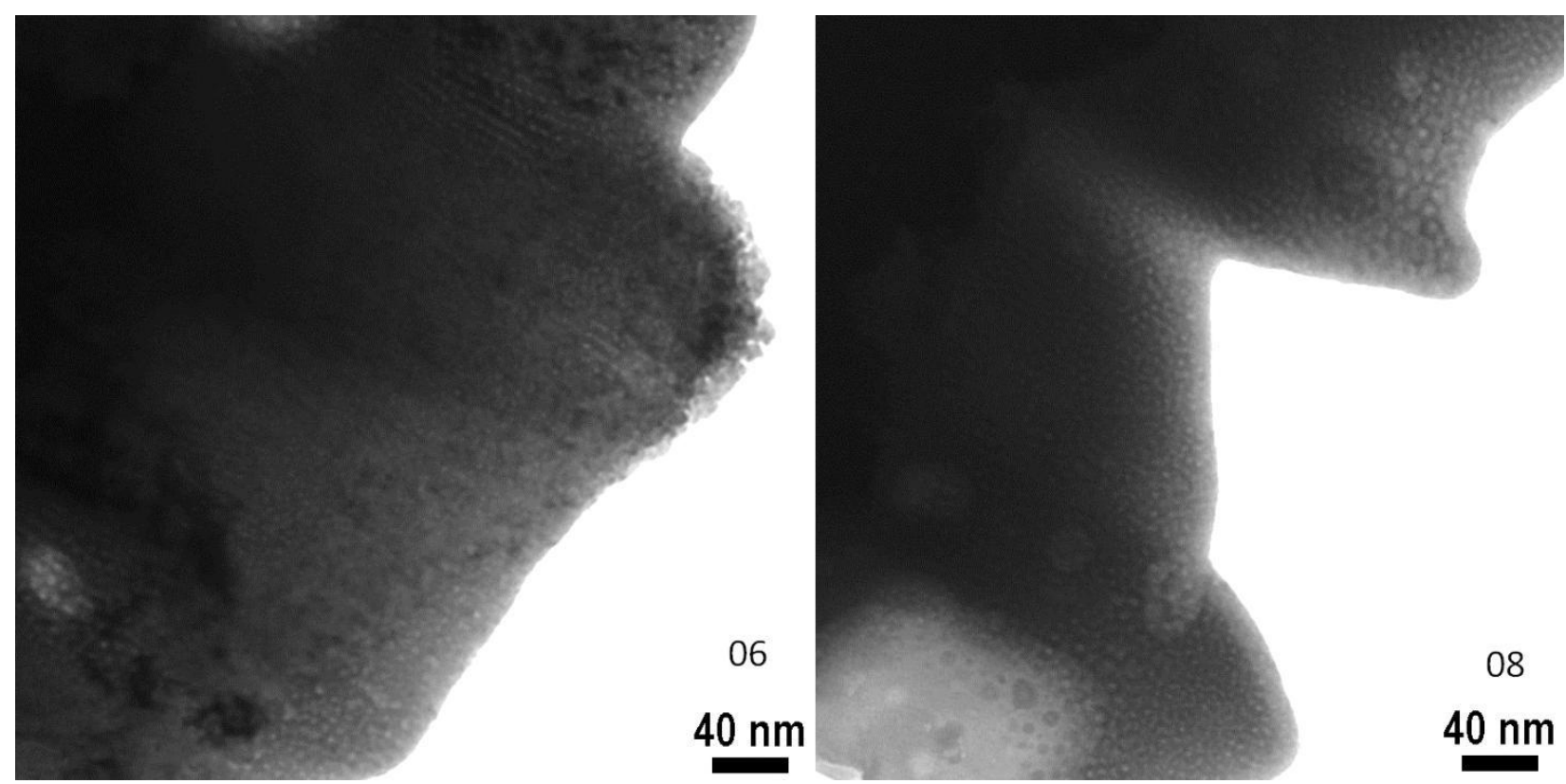

(Figure 3)

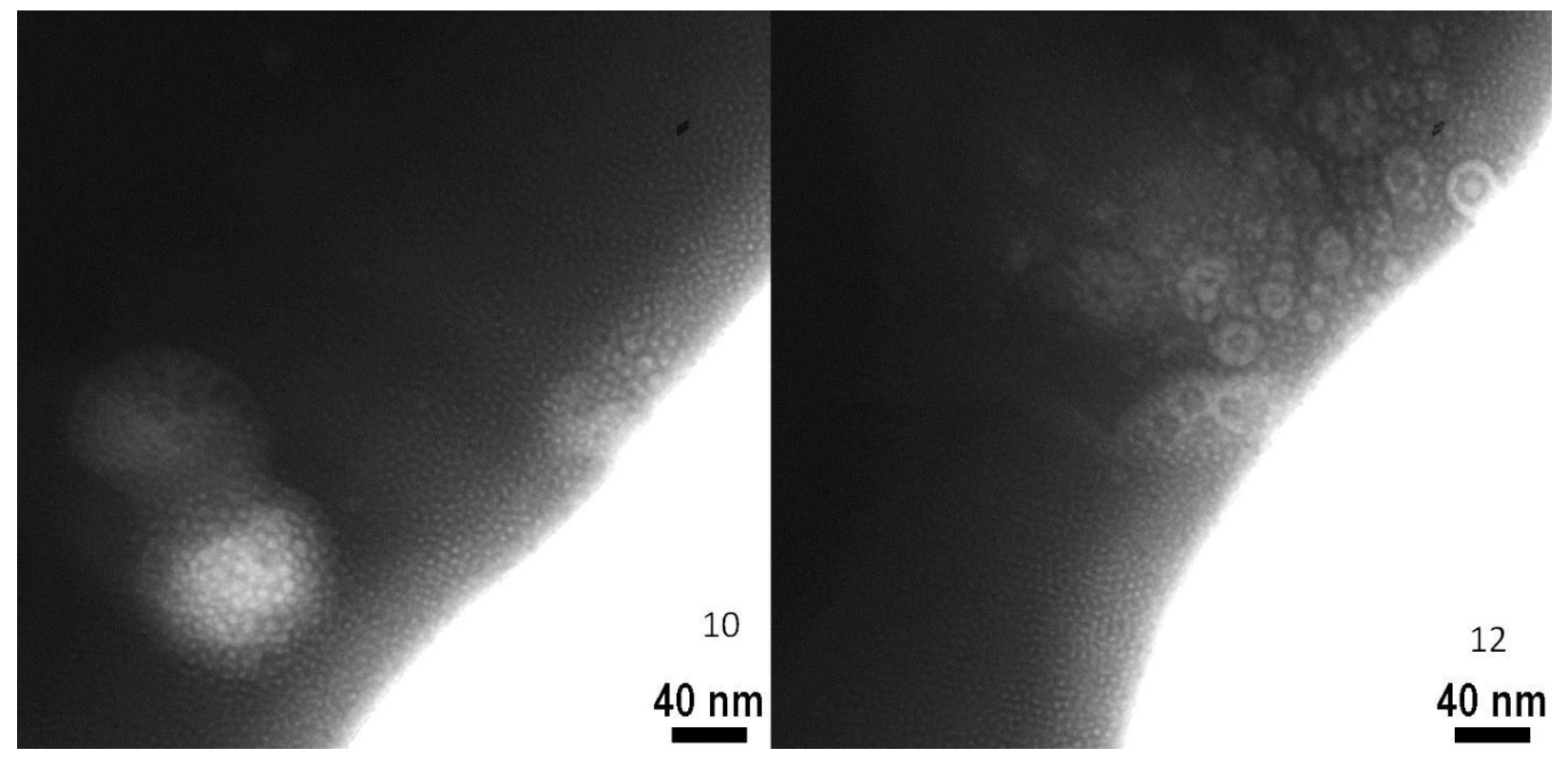

(Figure 4) 


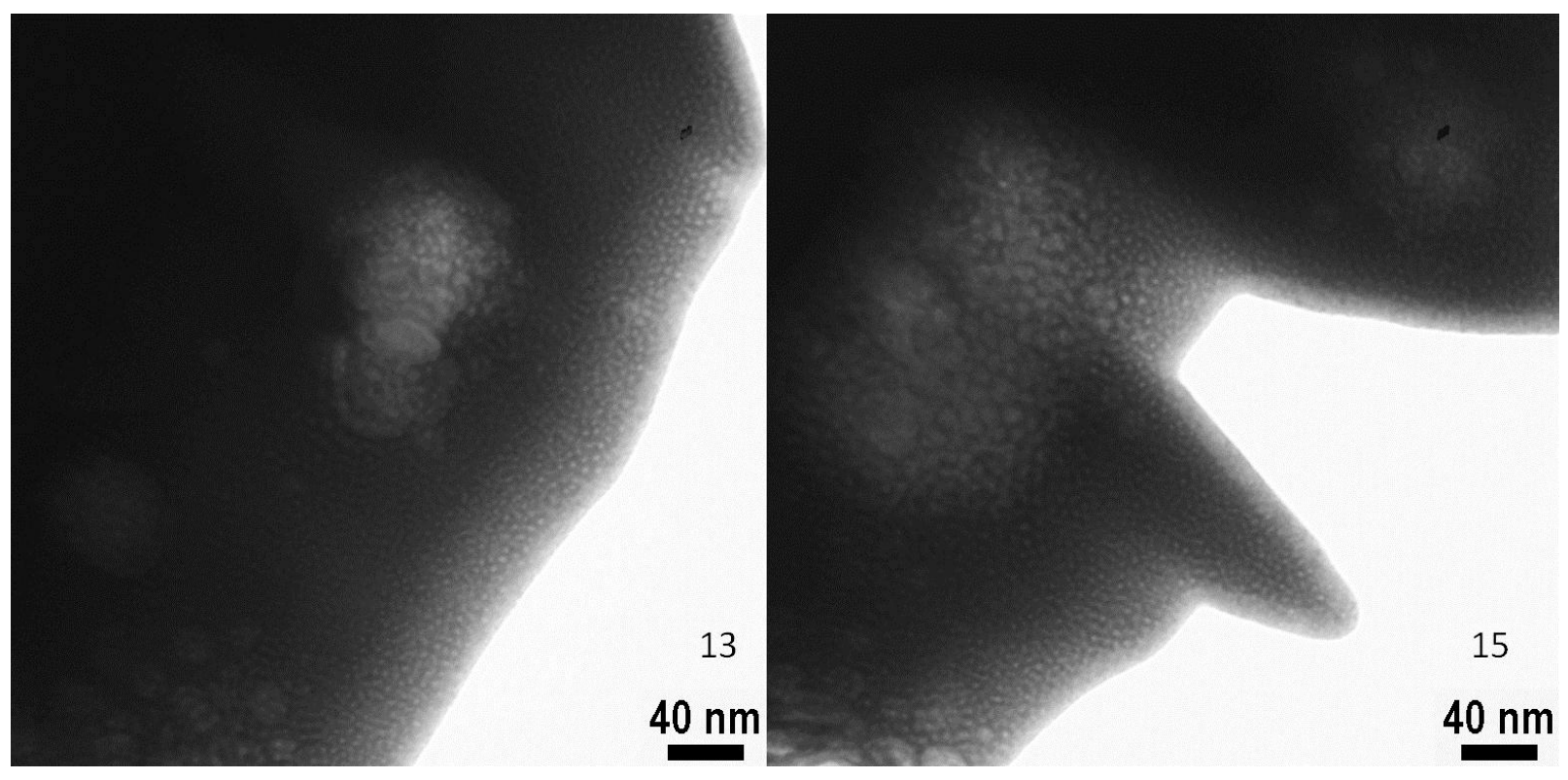

(Figure 5)

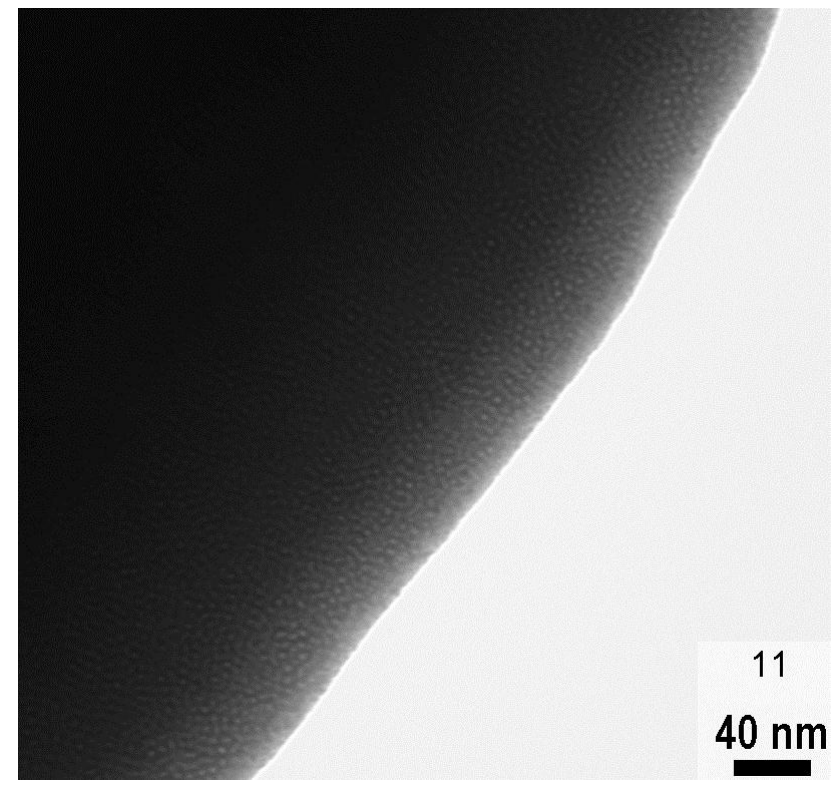

(Figure 6) 


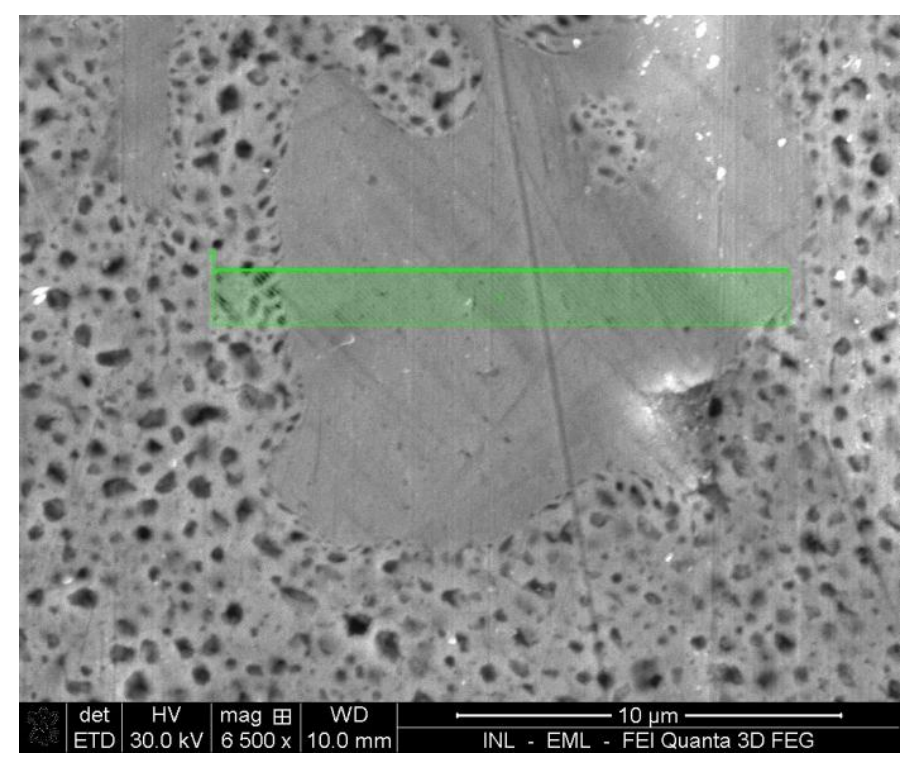

(Figure 7)

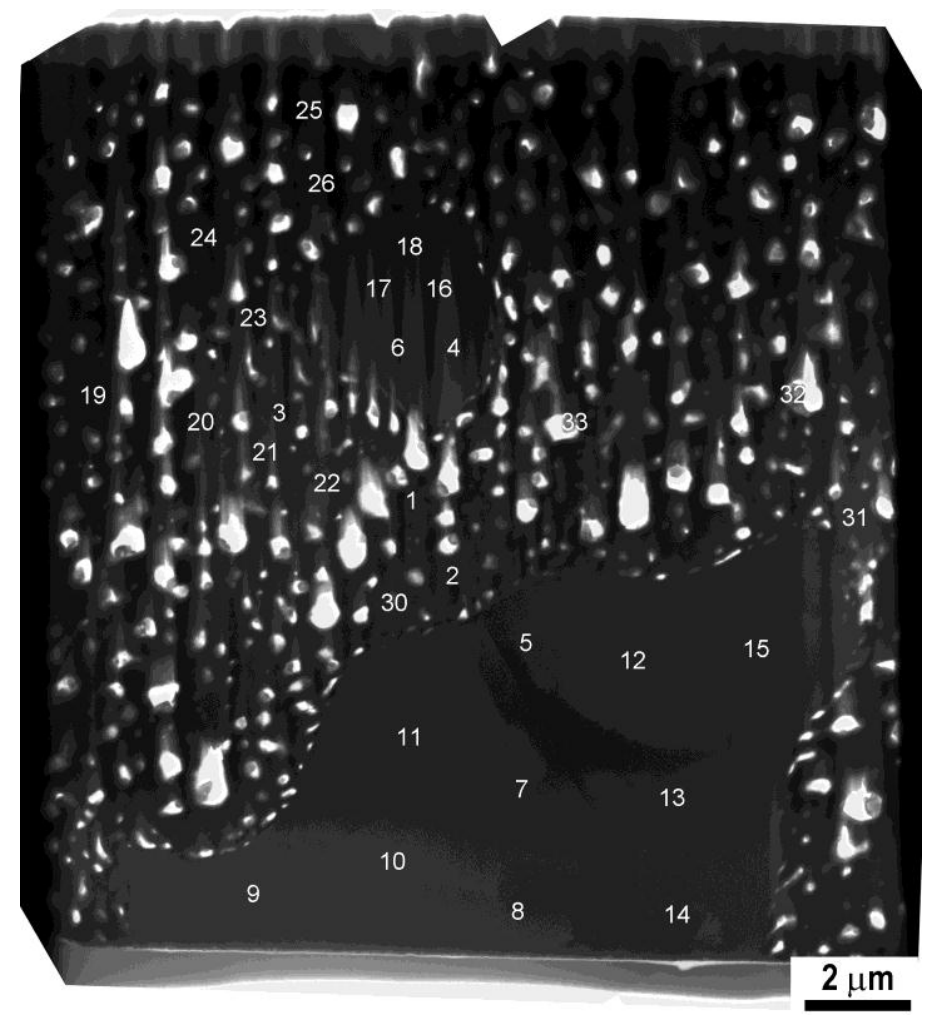

(Figure 8) 


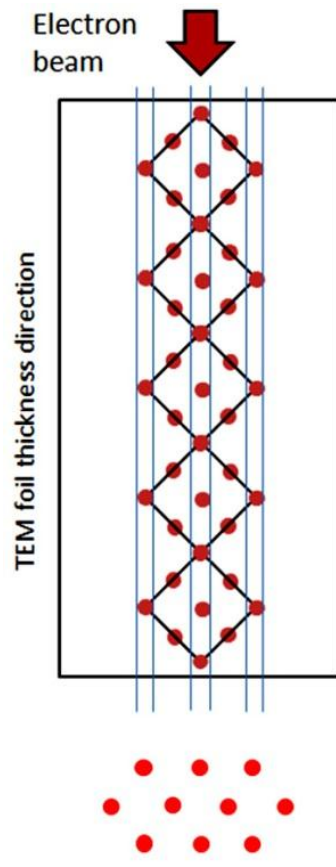

Projected image of rows of GBS bubbles stacked along [011] of bcc U-Mo fuel grain.

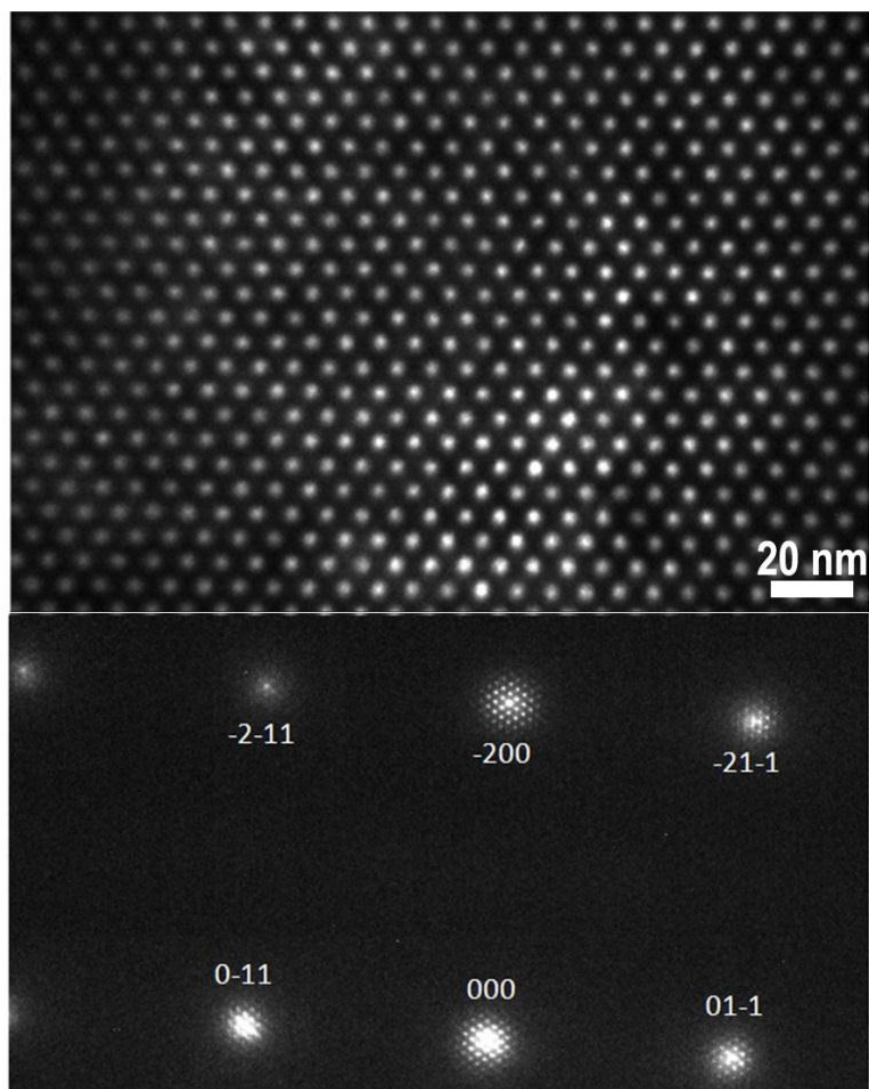

(Figure 9) 


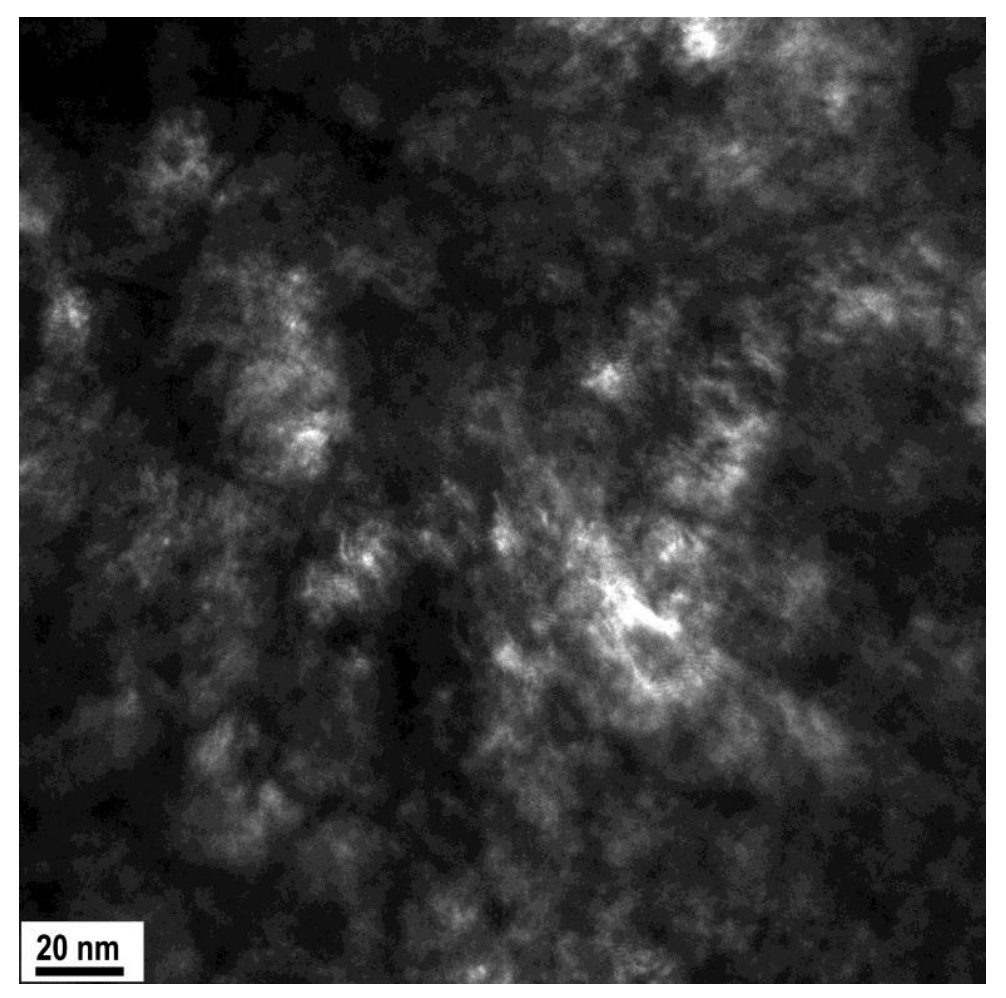

(Figure 10)

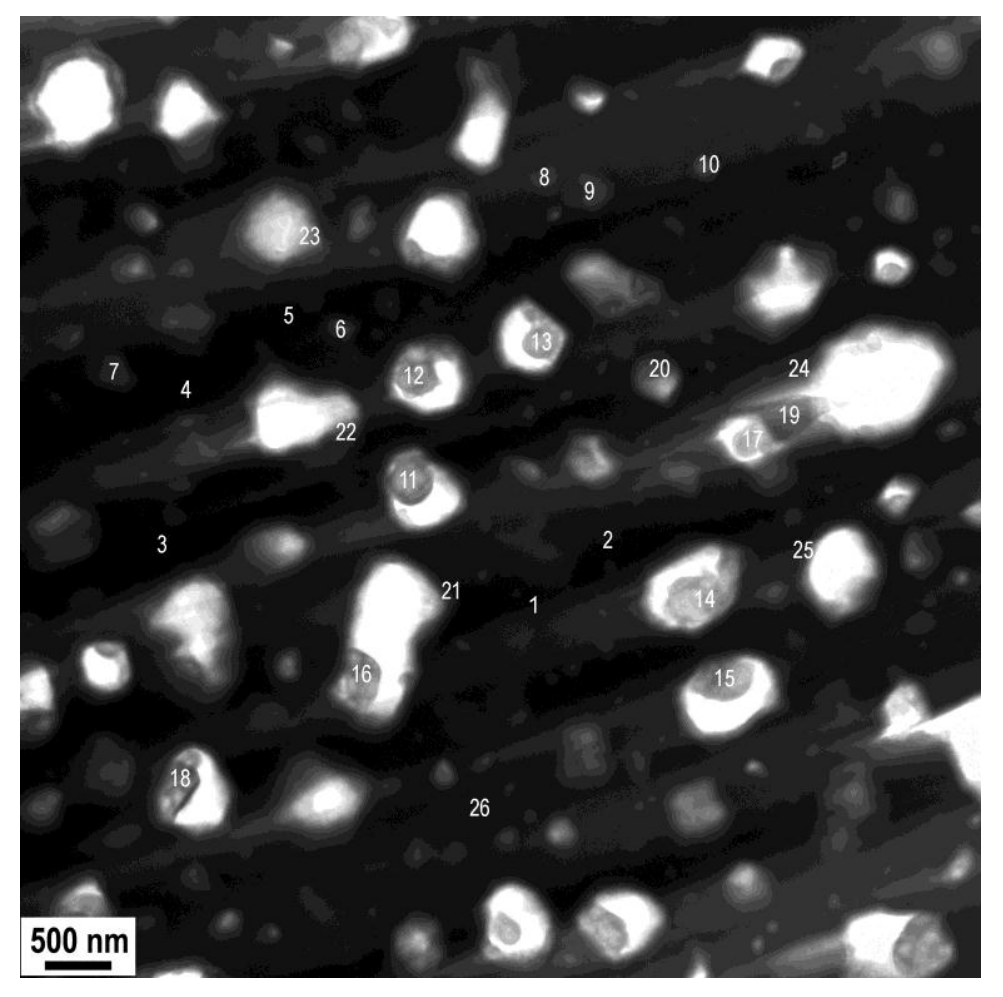

(Figure 11) 


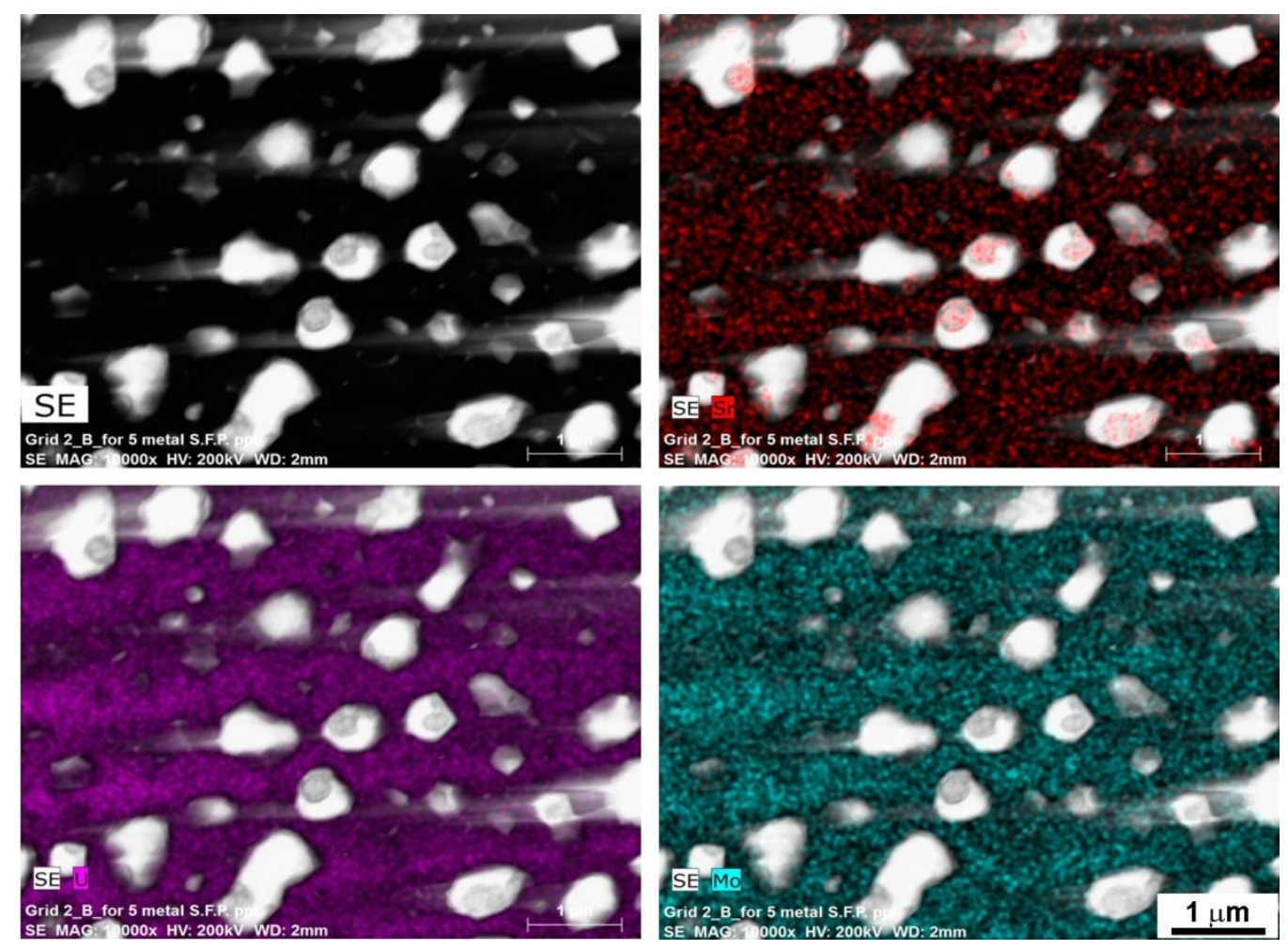

(Figure 12)

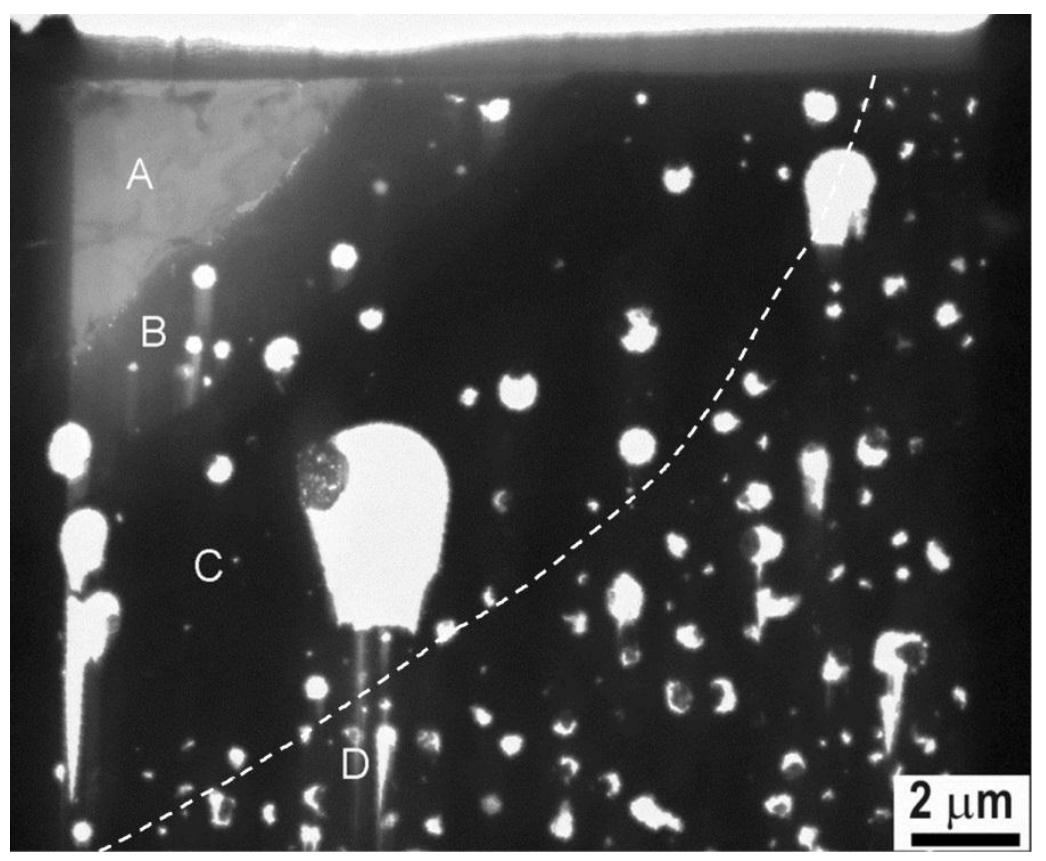

(Figure 13) 


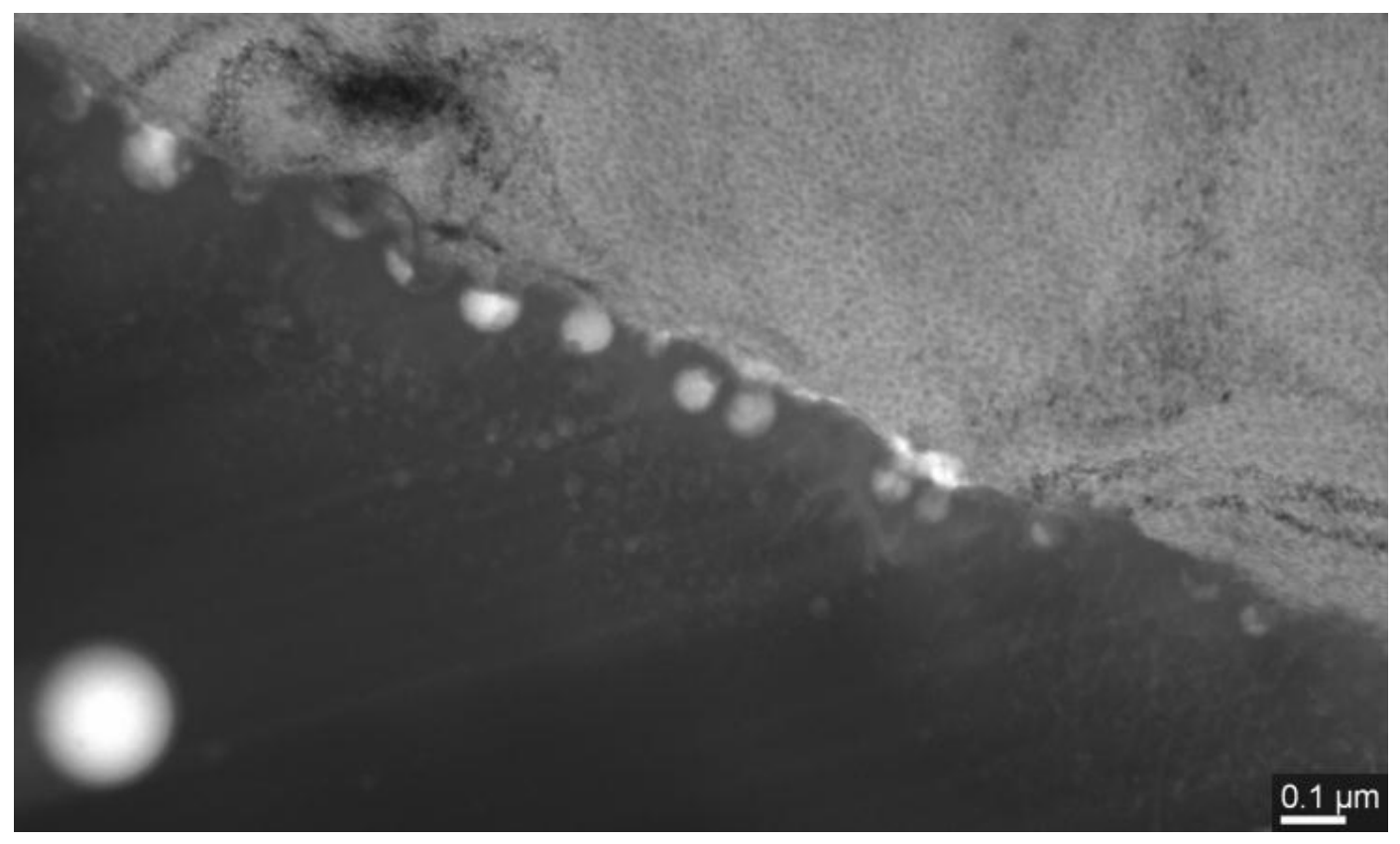

(Figure 14)

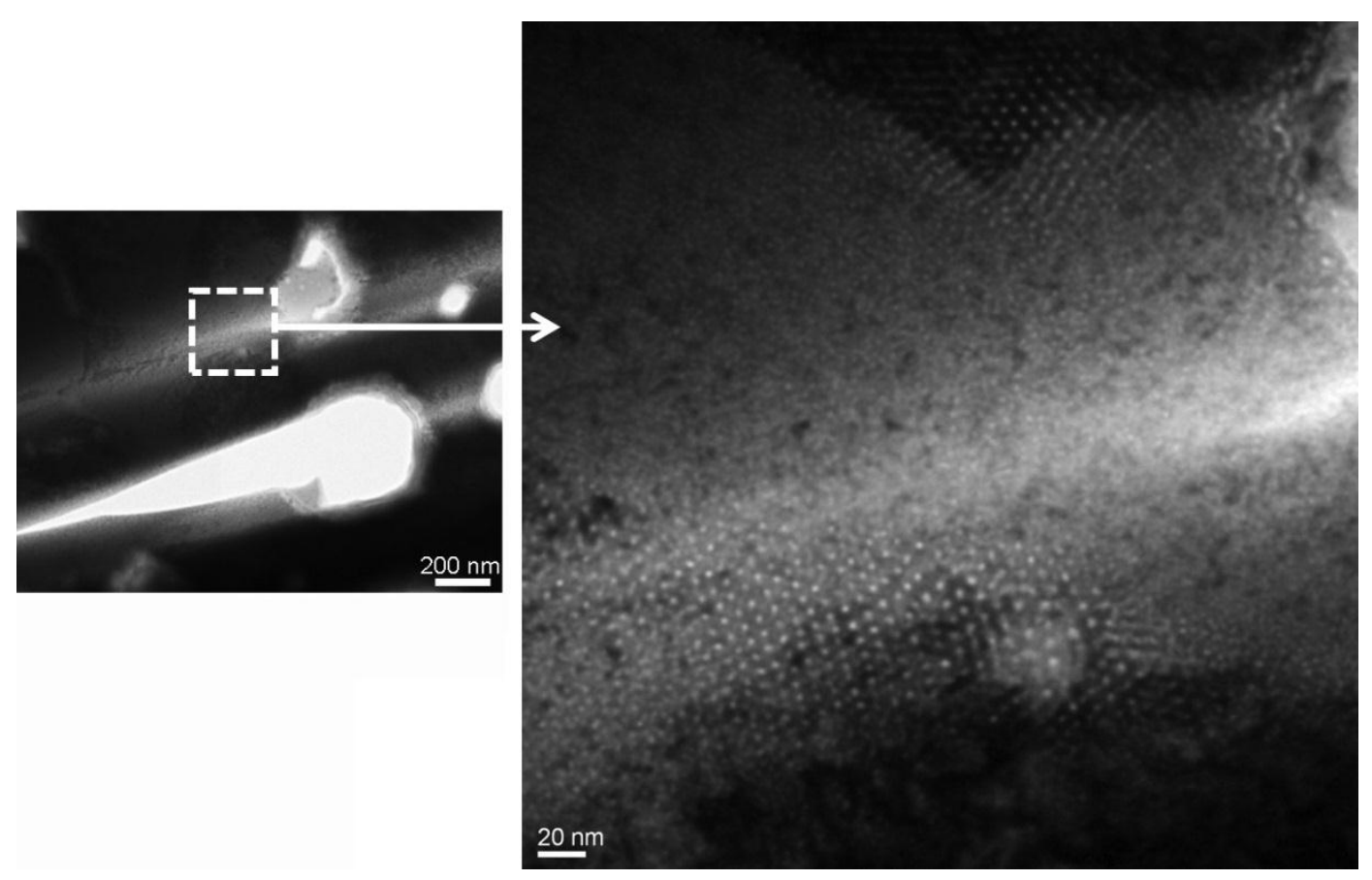

(Figure 15) 

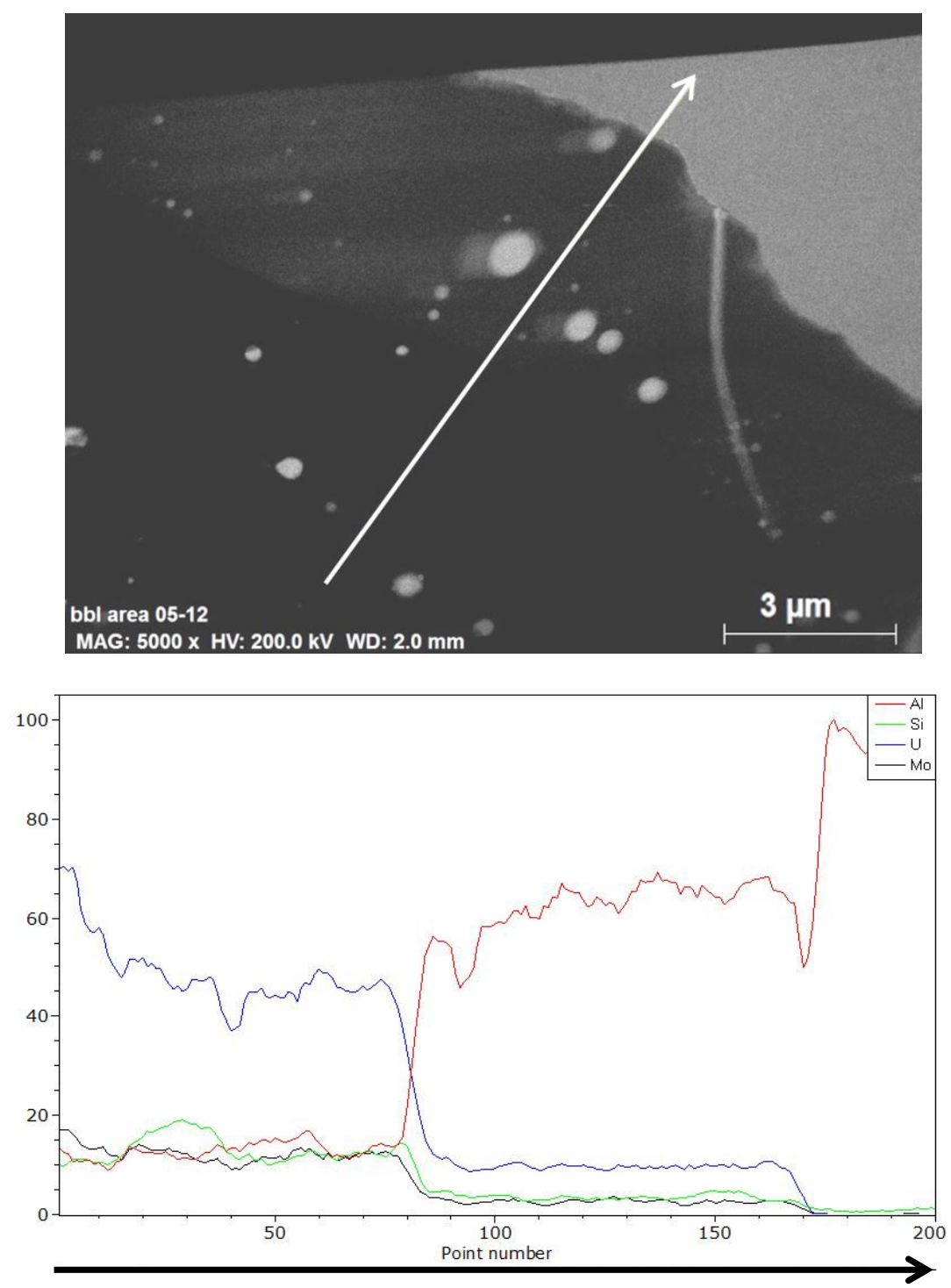

(Figure 16) 

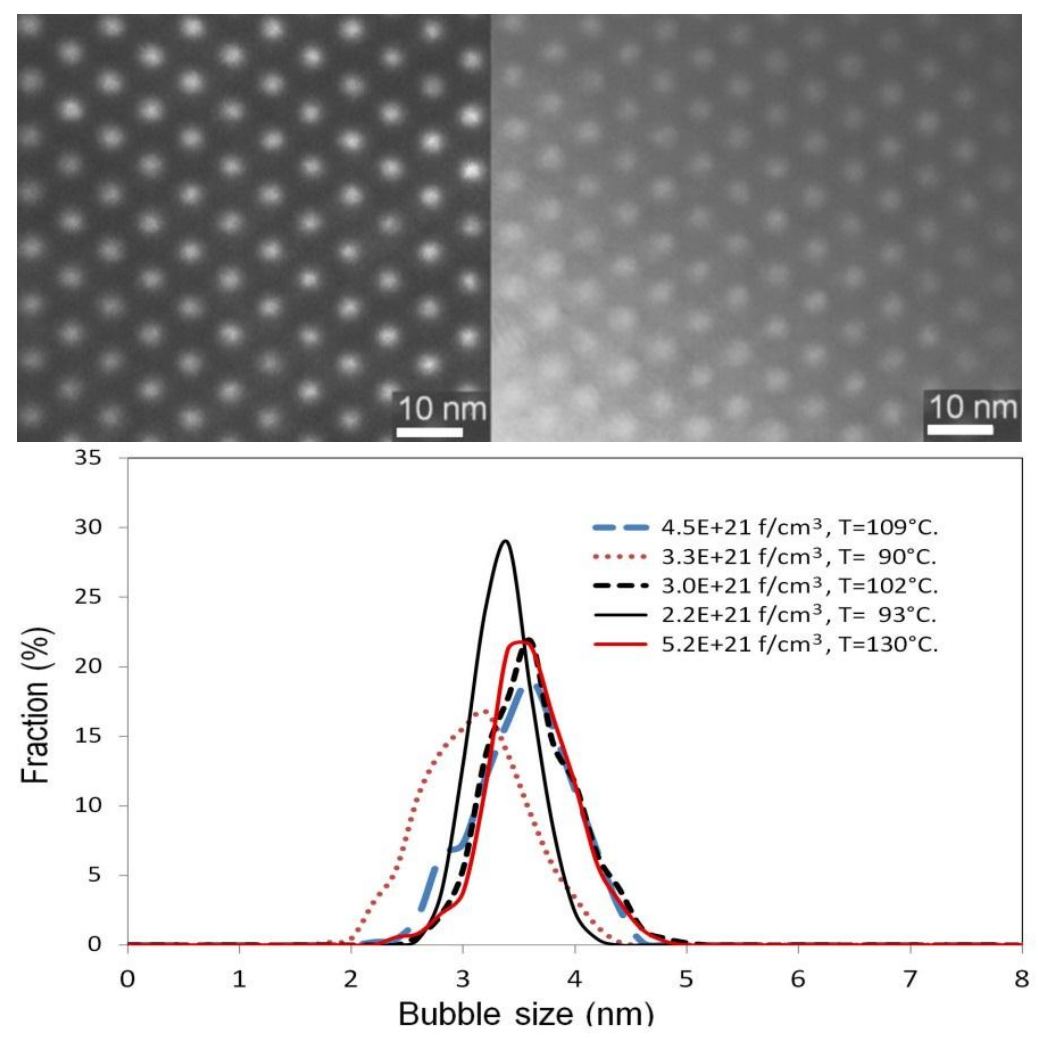

(Figure 17) 


\section{References}

${ }^{1}$ S. Van den Berghe, W. Van Renterghem, A. Leenaers, J. Nucl. Mater. 375 (2008) 340-346.

2 J. Gan, D.D. Keiser Jr., D.M. Wachs, A.B. Robinson, B.D. Miller, J. Nucl. Mater. 396 (2010) 234-239.

3 J. Gan, D.D. Keiser Jr., B.D. Miller, J.F. Jue, A.B. Robinson, J.W. Madden, P.G. Medvedev, D.M. Wachs, J. Nucl. Mater. 419 (2011) 97-104.

${ }^{4}$ B.D. Miller, J. Gan, J. Madden, J.F. Jue, A.B. Robinson, D.D. Keiser Jr., J. Nucl. Mater. 424 (2012) 3842.

${ }^{5}$ C.L. Clark, J.F. Jue, G.A. Moore, N.P. Hallinan, B.H. Park, D.E. Burker, RERTR-2006, in: $28^{\text {th }}$ International Meeting on Reduced Enrichment For Research and Test Reactors, Cape Town, South Africe, October 29 - November 2, 2006.

${ }^{6}$ D.D. Keiser Jr., J.F. Jue, A.B. Robinson, M.R. Finlay, RRFM-2008, in: $14^{\text {th }}$ International Meeting on Research Reactor Fuel Management, European Nuclear Society, Hamburg, Germany, March 2-5, 2008.

${ }^{7}$ M.K. Meyer, G.L. Hofman, S.L. Hayes, C.R. Clark, T.C. Wiencek, J.L. Snelgrove, R.V. Strain, K.H. Kim, J. Nucl. Mater. 304 (2002) 221-236.

${ }^{8}$ F. Mazaudie, C. Proye, F. Hodaj, J. Nucl. Mater. 377 (2008) 476-485.

9 J. Gan, D.D. Keiser Jr., B.D. Miller, A.B. Robinson, J.F. Jue, P. Medvedev, D.M. Wachs, J. Nucl. Mater. 424 (2012) 43-50.

${ }^{10} \mathrm{Hj}$. Matzke and H. Blank, J. Nucl. Mater. 166 (1989) 120.

${ }^{11}$ L.E. Thomas, C.E. Beyer and L.A. Charlot, J. Nucl. Mater. 188 (1992) 80-89.

${ }^{12}$ Y.S. Kim, H.J. Ryu, G.L. Hofman, S.L. Hayes, M.R. Finley, D.M. Wachs, G.S. Chang, RERTR 2006, Cape Town, South Africa, <http://www.rertr.anl.gov/RERTR28/

PDF/S15-1_Kim.pdf>.

${ }^{13}$ D. Keiser, Jr., B. Miller, J. Jue, J. Gan, A. Robinson, P. Medvedev, J. Madden, M. Teague, and D. Wachs, "SEM Characterization of the High Burn-up Microstructure of U-7Mo Alloy," Proceedings of the Research Reactor Fuel Management Conference, Ljubljana, Slovenia, March 30-April 3, 2014.

${ }^{14}$ David B. Williams and C. Barry Carter, Transmission Electron Microscopy, Plenum Publishing Co., New York, 1996.

15 Okamoto H., ID No. 901671, Binary Alloy Phase Diagrams, $2^{\text {nd }}$ Edition, Editor-in-Chief: T.B. Massalski, 1990, ASM International, Alloy Phase Diagram Section, Materials Park, Ohio, U.S.A.

${ }^{16}$ C.A.W. Peterson, W.J. Steele, S.L. DiGiallonardo, "Isothermal Transformation Study of Some Uranium-Base Alloys", Report: UCRL-7824, Metals, Ceramics, and Materials, UC-25, TID-4500 (34 ${ }^{\text {th }}$ Ed.), Lawrence Radiation Laboratory, Livermore, California, August, 1964.

17 J-F. Jue, D.D. Keiser Jr., C.R. Breckenridge, G.A. Moore, M.K. Meyer, J. Nucl. Mater. 448 (2014) 250-258. 